\title{
Effects of intrauterine infusion of seminal plasma at artificial insemination on fertility of lactating Holstein cows
}

\author{
W. G. Ortiz, ${ }^{1}$ J. A. Rizo, ${ }^{1}$ L. R. Carvalheira, ${ }^{2}$ B. M. S. Ahmed, ${ }^{1 *}$ E. Estrada-Cortes, ${ }^{1}$ B. R. Harstine,${ }^{3}$ \\ J. J. Bromfield, ${ }^{1}$ and P. J. Hansen ${ }^{1} \dagger$ \\ ${ }^{1}$ Department of Animal Sciences and D. H. Barron Reproductive and Perinatal Biology Research Program, University of Florida, \\ Gainesville 32611-0910 \\ ${ }^{2}$ Departmento de Clínica e Cirurgia Veterinárias, Universidade Federal de Minas Gerais, BeloHorizonte, MG, Brazil CEP $31270-901$ \\ ${ }^{3}$ Select Sires Inc., Plain City, OH 43064
}

\section{ABSTRACT}

An inflammatory response is induced in the reproductive tract by deposition of semen during natural mating. This response might facilitate establishment and maintenance of pregnancy and alter the phenotype of the offspring by modifying the microenvironment of the reproductive tract. Here, we hypothesized that intrauterine infusion of $0.5 \mathrm{~mL}$ of seminal plasma at the time of artificial insemination (AI) in first-service lactating Holstein cows will improve pregnancy success after insemination. Cows were inseminated (511 primiparous cows inseminated with X-sorted semen, 554 multiparous cows inseminated with X-sorted semen, and 627 multiparous cows inseminated with conventional semen) using the Double-Ovsynch protocol. Cows were randomly assigned to receive intrauterine infusion of either $0.5 \mathrm{~mL}$ of seminal plasma or saline immediately after AI. There was no overall effect of seminal plasma infusion on the percentage of inseminated cows diagnosed pregnant at d 32 or 60 after AI, pregnancy loss, or percent of inseminated cows calving. If cows were inseminated with conventional semen, seminal plasma reduced pregnancies at $\mathrm{d} 32$ and tended to reduce calvings. There was no effect of seminal plasma if cows were inseminated with $\mathrm{X}$-sorted semen. Seminal plasma infusion increased the birth weight of heifer calves born using $\mathrm{X}$-sorted semen but not conventional semen. These results do not support a beneficial effect of seminal plasma on pregnancy success after AI, but exposure to seminal plasma may program fetal development to affect phenotype at birth.

Key words: seminal plasma, fertility, conception, pregnancy, developmental programming

Received January 3, 2019

Accepted March 27, 2019.

*Present address: Department of Animal Sciences, University of Sulaimani, Sulaymaniyah, Iraq.

†Corresponding author: pjhansen@ufl.edu

\section{INTRODUCTION}

An inflammatory response is induced in the reproductive tract by deposition of semen during natural mating (see reviews by Robertson, 2005; Schuberth et al., 2008; Katila, 2012; Bromfield, 2016). The inflammatory response to mating is less well described in cattle than in some other species but includes accumulation of neutrophils (Howe and Black, 1963; Mattner, 1968) and, based on responses to seminal plasma, changes in gene expression in the endometrium (Ibrahim et al., 2019).

The inflammatory response to mating helps clear microorganisms and spermatozoa from the reproductive tract (Hansen et al., 1987; Alghamdi et al., 2009). In addition, it has been proposed that inflammatory or immune responses to semen could facilitate the establishment and maintenance of pregnancy by modifying the microenvironment of the reproductive tract (Robertson, 2005; Bromfield, 2016). In the mouse, females mated with males lacking seminal vesicles had reduced conception rates, embryos with poor development to the blastocyst stage and low implantation rates, and offspring that experienced sex-dependent changes in postnatal phenotypes (Bromfield et al., 2014).

For other species, the importance of seminal plasma for modulating female fertility is unclear. Removal of individual accessory sex glands had no effect on fertilization in the golden hamster but occurrence of embryonic death at d 9 of pregnancy was increased when females were mated with males in which either the ampullary gland or ventral prostate was surgically ablated (Chow and O, 1989). Removal of seminal vesicles had no effect on fertility of bulls (Faulkner et al., 1968) or boars (Davies et al., 1975) used for natural mating. However, intrauterine infusion of seminal plasma increased the number and viability of embryos recovered at $\mathrm{d} 5$ and 9 after AI in gilts (O'Leary et al., 2004). In the pig (Rozeboom et al., 2000) and mare (Alghamdi et al., 2004), addition of seminal plasma to extended semen improved fertility in gilts in which inflammation was 
induced by intrauterine infusion of LPS or killed sperm (Rozeboom et al., 2000) and mares in which inflammation was induced by intrauterine infusion of killed sperm (Alghamdi et al., 2004). The observation that there was no beneficial effect of seminal plasma in the absence of inflammation in gilts (Rozeboom et al., 2000) suggests that beneficial effects of seminal plasma may depend on the degree of inflammation in the uterus.

The effectiveness of AI using extended semen in cattle indicates that deposition of more than minuscule amounts of seminal plasma are not required for establishment of pregnancy. There is some indication, however, that seminal plasma may play a modulatory role in the cow to create a uterine environment conducive to fertility. Odhiambo et al. (2009) observed that pregnancy per AI was numerically higher for lactating dairy cows receiving $0.5 \mathrm{~mL}$ of seminal plasma at the time of insemination $(37.8 \%)$ than for cows receiving no treatment $(33.2 \%)$. In the same report, pregnancy per AI for beef cows was also numerically higher for cows receiving seminal plasma infusion than for cows receiving infusion of BSA (58.1 vs. $55.1 \%$ in one series of studies and 67.0 vs. $59.5 \%$ in another study) or no treatment (61.4 vs. $52.4 \%)$.

The present experiment was performed to further evaluate the efficacy of seminal plasma for increasing fertility of cows. The hypothesis was that intrauterine infusion of $0.5 \mathrm{~mL}$ of seminal plasma at the time of AI in first-service lactating Holstein cows will improve the percentage of cows pregnant to first-service AI, reduce subsequent pregnancy losses, and increase the percentage of inseminated cows that calve. Effects of intrauterine infusion of seminal plasma on birth weight of heifer calves were also evaluated because of a finding that mice born from males without seminal vesicles had altered postnatal phenotypes (Bromfield et al., 2014).

\section{MATERIALS AND METHODS}

\section{Animals and Management}

The experiment was performed on a commercial dairy farm in north-central Florida (Alliance Dairy, Trenton, FL; $29^{\circ} 36^{\prime} 54^{\prime \prime} \mathrm{N} 82^{\circ} 49^{\prime} 4^{\prime \prime}$ W) with inseminations performed from November 2017 to February 2018. All experiments were conducted in accordance with the principles and specific guidelines presented in Guidelines for the Care and Use of Agricultural Animals in Research and Teaching (FASS, 2010). Cows were housed in freestall barns equipped with fans and soakers, milked 3 times a day, and fed a TMR. The experiment followed the standard reproductive management protocols used on this farm. All procedures, including injections, pregnancy diagnosis, and timed AI (TAI) were performed while cows were restrained in self-locking head gates at the feed line. A total of 1,692 first-service lactating Holstein cows [511 primiparous cows inseminated with Xsorted semen, 554 multiparous cows inseminated with $\mathrm{X}$-sorted semen, and 627 multiparous cows inseminated with conventional semen] were subjected to TAI using the Double-Ovsynch procedure (Souza et al., 2008) for first service at 75 to $82 \mathrm{~d}$.

\section{Treatments}

Each cow was inseminated with a straw of semen of the farm's choice. Bulls used for X-sorted semen were different from bulls used for conventional semen. The total number of sires used was 18 for X-sorted semen and 21 for conventional semen. Cows were assigned randomly to receive an intrauterine infusion of either a straw of pooled seminal plasma $(\mathrm{n}=860)$ or saline $[0.9 \%(\mathrm{wt} / \mathrm{vol}) \mathrm{NaCl} ; \mathrm{n}=832]$ immediately after insemination. In addition, for $5 \mathrm{wk}$ of the study (January-February), a third group of cows was included, in which cows were inseminated without infusion of seminal plasma or saline $(\mathrm{n}=249)$. Treatments were packaged in $0.5-\mathrm{mL}$ straws by Select Sires Inc. (Plain City, $\mathrm{OH})$ following all Certified Semen Services (https:// www.naab-css.org/uploads/userfiles/files/CSSMinReq -Jan2014201607-ENG.pdf) minimum requirements for disease control of semen produced for AI. To prepare the seminal plasma treatment, semen was obtained from 44 Holstein bulls (ranging in age from 1.3 to $7.9 \mathrm{yr}$ ) by artificial vagina on a single day. Semen was pooled, antibiotics (Shin et al., 1988) added, and then semen was centrifuged at $1,500 \times g$ for $15 \mathrm{~min}$. The seminal plasma supernatant was collected, passed through a $3-\mu \mathrm{m}$ pleated filter to eliminate remaining sperm, packaged in straws, and frozen in liquid nitrogen. The sterile saline control solution was packaged in $0.5-\mathrm{mL}$ semen straws and frozen in liquid nitrogen. The seminal plasma and saline were packaged in straws of different colors with the color code representing the specific treatment (unknown to technicians). Randomization was achieved by alternating the straw color for each consecutive cow.

At the time of treatment, straws of seminal plasma or saline were thawed at $36.5^{\circ} \mathrm{C}$, loaded in $\mathrm{AI}$ guns, and kept in warmer pockets until the time of infusion. Treatments were infused into the uterine body.

\section{Pregnancy Outcomes}

Pregnancy diagnosis was performed by transrectal ultrasonography at d $32( \pm 4 \mathrm{~d})$ and d $60( \pm 7 \mathrm{~d})$ after insemination. A cow was determined pregnant when an embryonic vesicle with a viable embryo (presence 
Table 1. List of quantitative real-time PCR primer sequences for target gene analysis

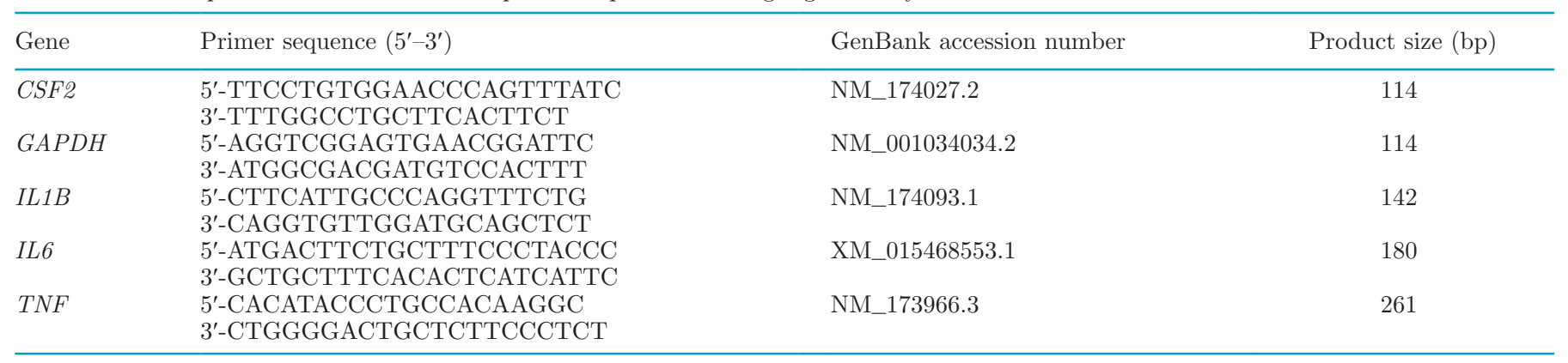

of heartbeat) was detected. Birth was recorded and the BW of heifer calves determined using an electronic WeightSouth VS-2501 scale (WeightSouth Inc., Asheville, $\mathrm{NC}$ ).

\section{Bioactivity of Seminal Plasma}

The bioactivity of seminal plasma used for intrauterine infusion was confirmed using in vitro culture. Briefly, 10 straws of seminal plasma were thawed and pooled under aseptic conditions; 10 straws of saline were also thawed and pooled. Bovine endometrial epithelial (BEND) cells (American Type Culture Collection, Manassas, VA) were cultured following the supplier's instruction in a 1:1 mixture of Dulbecco's minimum essential medium (DMEM) and Ham's F12 Nutrient Mixture medium supplemented with $1.5 \mathrm{~g} / \mathrm{L}$ sodium bicarbonate, $0.034 \mathrm{~g} / \mathrm{L}$ D-valine, $10 \%$ fetal bovine serum, and 10\% horse serum (all from Fisher Scientific, Waltham, MA). Cells were plated at $10^{5}$ cells $/ \mathrm{mL}$ in 24-well culture plates (TPP, Trasadingen Switzerland) at a final volume of $500 \mu \mathrm{L}$ for $24 \mathrm{~h}$ at $38.5^{\circ} \mathrm{C}$ in a humidified $5 \% \mathrm{CO}_{2}$ environment. Treatments containing either $1 \%$ (vol/vol) saline, $1 \%$ (vol/vol) seminal plasma, or culture medium alone were applied to BEND cells for $24 \mathrm{~h}$. Following treatment, cells were washed with warm Dulbecco's PBS and stored in RLT Lysis Buffer (Qiagen, Hilden, Germany) at $-80^{\circ} \mathrm{C}$ until processing to collect total cellular RNA.

Extraction of RNA was performed using the RNeasy Mini Kit (Qiagen) according to the manufacturer's instructions. The concentration was quantified using a NanoDrop ND1000 spectrophotometer (Fisher Scientific), and a total of $1 \mu \mathrm{g}$ of RNA was used for reverse transcription using the Verso cDNA kit (Fisher Scientific) according to manufacturer's instructions. Reverse transcription was performed for 1 cycle at $42^{\circ} \mathrm{C}$ for 30 min, followed by enzyme inactivation at $95^{\circ} \mathrm{C}$ for $2 \mathrm{~min}$. The resultant cDNA was diluted 1:3 in molecular-grade water and stored at $-20^{\circ} \mathrm{C}$.
Quantitative real-time PCR was performed in $20 \mu \mathrm{L}$ reactions using iTaq Universal SYBR green chemistry (Bio-Rad, Hercules CA) with $100 \mathrm{n} M$ concentrations of each forward and reverse primer. Primer details are described in Table 1. A Bio-Rad CFX Connect light cycler was used to perform quantitative PCR using a 2 -step protocol. Thermal cycling conditions were as follows: initial denaturation/enzyme activation at $95^{\circ} \mathrm{C}$ for $30 \mathrm{~s}$, followed by 40 cycles of denaturation at $95^{\circ} \mathrm{C}$ for 5 $\mathrm{s}$, and annealing/extension for $30 \mathrm{~s}$ at $60^{\circ} \mathrm{C}$. Each PCR reaction was followed by melt curve analysis to ensure single product amplification. A no-template negative control was used in place of cDNA to determine nonspecific amplification. Relative expression for genes of interest were calculated using the $2^{-\Delta \mathrm{Ct}}$ method relative to that of the housekeeping gene $(G A P D H)$.

\section{Statistical Analysis}

Gene expression data were analyzed on log-transformed values by ANOVA using the GLM procedure of SAS software (version 9.4; SAS Institute Inc., Cary, NC). The model included treatment, which was partitioned into individual degree-of-freedom comparisons using orthogonal contrasts to compare no treatment and saline to seminal plasma and no treatment to saline.

Data on pregnancy per AI and pregnancy loss were analyzed with the GLIMMIX procedure of SAS software (version 9.4; SAS Institute Inc.) with the dependent variable pregnancy outcome (pregnant, nonpregnant), which was modeled as having a binomial distribution. Two analyses were performed. The first included all cows assigned to the saline or seminal plasma treatments. The model included effects of group (primiparous-X-sorted semen; multiparous-X-sorted semen; multiparous-conventional semen), seminal plasma treatment, and their interaction. Preplanned contrasts were used to separate variation due to group into effects due to parity (primiparous-X-sorted semen vs. 
multiparous-X-sorted semen) and semen type (multiparous-X-sorted semen vs. multiparous-conventional semen) and effects due to group $\times$ treatment into parity $x$ treatment and semen type $\times$ treatment. Note that the contrasts are not orthogonal to each other. The second analysis included cows from the weeks in which 3 treatment groups (no treatment, saline, seminal plasma) were included. The model was the same as above except orthogonal contrasts were also used to partition effects of treatment into the following comparisons: no treatment versus (saline + seminal plasma) and saline versus seminal plasma.

The GLIMMIX procedure was also used to analyze effects of treatment on gestation length of all heifer calves $(\mathrm{n}=439)$ and birth weight of all live singleton heifer calves $(\mathrm{n}=427)$. Variables were considered continuous. Models were the same as described above except that sire was also included in the model as a random variable.

\section{RESULTS}

\section{Effect of Seminal Plasma on BEND Cell Gene Expression}

To verify biological activity of seminal plasma, BEND cells were exposed for $24 \mathrm{~h}$ to either $1 \%$ ( $\mathrm{vol} /$ vol) saline, $1 \%$ (vol/vol) seminal plasma, or complete culture medium alone as a negative control and expression of selected genes determined (Figure 1). Exposure to seminal plasma increased expression of IL- $\beta 1$ (ILB1) and IL-6 (IL6) by 8.9- and 22.8-fold compared with the negative control or saline, respectively (Figure 1C, D; $P<0.0001)$. Expression of colony-stimulating factor 2 (CSF2) or tumor necrosis factor (TNF) were unaffected by seminal plasma treatment (Figure 1A, B; $P>0.10$ ).
Exposure of BEND cells to saline had no effect on gene expression.

\section{Pregnancy per Al}

Pregnancy outcomes for each of the 3 groups of cows used (primiparous-X-sorted semen, multiparous-Xsorted semen, and multiparous-conventional semen) are shown in Table 2. Group affected pregnancy per AI at d $32(P=0.017)$ and $60(P=0.004)$ after insemination but not calving per AI $(P=0.427)$. Contrasts were used to partition effects of group into an effect of parity (primiparous-X-sorted semen vs. multiparous-X-sorted semen) and semen type (multiparous-X-sorted semen vs. multiparous conventional semen). Although pregnancy per AI at $\mathrm{d} 32$ tended $(P=0.098)$ to be lower for primiparous cows than multiparous cows, effects of parity were not significant for pregnancy outcomes at other times. Semen type tended $(P=0.059)$ to affect pregnancy per AI at d 60 but not at other times, with pregnancy per AI tending to be lower for cows inseminated with X-sorted semen. There was no main effect of treatment with seminal plasma at any time measured. There was, however, an interaction between seminal plasma treatment and semen type for pregnancy per AI at d $32(P=0.041)$ and calving $(P=0.098)$ : seminal plasma reduced pregnancies if cows were inseminated with conventional semen but not if cows were inseminated with X-sorted semen.

\section{Pregnancy Loss}

Data on pregnancy loss are shown in Table 2. Group affected, or tended to affect, pregnancy loss from d 32 to $60(P=0.073), 60$ to calving $(P=0.007)$, and $\mathrm{d} 32$ to calving $(P=0.096)$. The effect of group on pregnancy
A

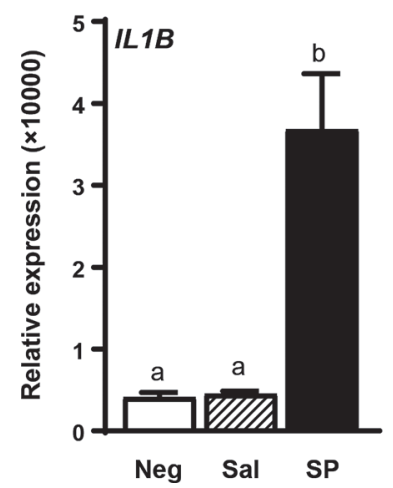

B

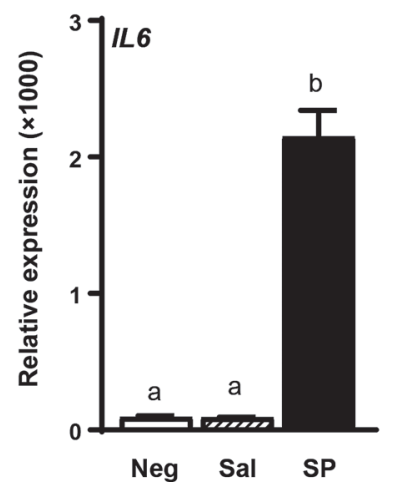

C

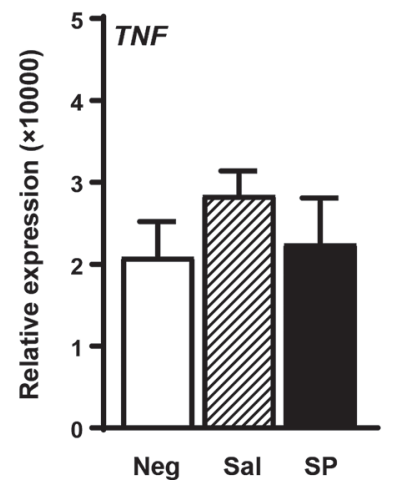

D

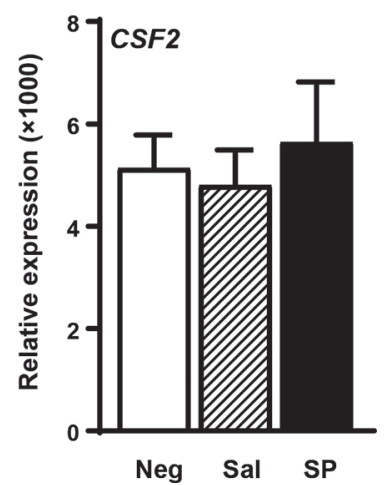

Figure 1. Effect of treatment of bovine endometrial epithelial (BEND) cells with seminal plasma on expression of selected genes. Expression of (A) IL1B, (B) IL6, (C) TNF, and (D) CSF2 in BEND cells treated for $24 \mathrm{~h}$ with complete culture medium as a negative control (Neg), $1 \%$ $\mathrm{vol} / \mathrm{vol}$ saline $(\mathrm{Sal})$, or $1 \%(\mathrm{vol} / \mathrm{vol})$ seminal plasma (SP). Data are presented as the mean relative expression \pm SEM from 7 independent experiments. Letters $(\mathrm{a}, \mathrm{b})$ above each bar indicate a significant difference across treatments $(P<0.0001)$. 
loss from d 32 to 60 was largely due to the effect of semen type, with $\mathrm{X}$-sorted semen being associated with higher pregnancy loss $(P=0.064)$. Effect of group on pregnancy loss after d 60 was due to higher pregnancy loss for multiparous cows. Pregnancy loss for multiparous cows inseminated with $\mathrm{X}$-sorted semen was higher than for primiparous cows inseminated with $\mathrm{X}$-sorted semen, whether measured from d 60 to calving $(P=$ $0.024)$ or from d 32 to calving $(P=0.048)$. Pregnancy loss was not affected by seminal plasma treatment. There was a tendency $(P=0.095)$ for an interaction with semen type for pregnancy loss from d 32 to 60 but not at other times. The interaction involved seminal plasma increasing pregnancy loss in multiparous cows treated with $\mathrm{X}$-sorted semen but not in primiparous cows inseminated with $\mathrm{X}$-sorted semen.

\section{Effect of Intrauterine Infusion on Fertility}

To determine whether intrauterine infusion itself affected fertility, a third group of cows that did not receive intrauterine infusion was included in the experiment for 5 wk of the study. There was no difference between pregnancy outcomes for this group compared with the 2 groups receiving intrauterine infusions. Overall, the fraction (\%) of cows pregnant at d 32 was $165 / 369(44.7 \%)$ for saline infusion, $165 / 368$ (44.8\%) for seminal plasma infusion, and 116/249 (46.6\%) for no infusion. For pregnancy at d 60, values were 162/369 (43.9\%) for saline infusion, 156/368 (42.4\%) for seminal plasma infusion, and 115/249 (46.2\%) for no infusion. For calving, values were $135 / 369(36.6 \%)$ for saline infusion, 133/368 (36.1\%) for seminal plasma infusion, and 92/249 (36.9\%) for no infusion.

\section{Gestation Length and Birth Weights of Heifer Calves}

The percent of calves born that were heifers was $51 \%$ $(140 / 274)$ for animals inseminated with conventional semen and $87 \%(357 / 407)$ for animals inseminated with X-sorted semen. Data on gestation lengths for 439 heifer deliveries and on birth weights of 427 singleton heifer calves that were live at birth were analyzed. Results are shown in Table 3. Gestation length was not affected by group, treatment, or the interaction. Birth weight was affected by group $(P=0.025)$. Use of contrasts indicated that the group effect was due to heavier birth weights for calves born from cows inseminated with $\mathrm{X}$-sorted semen than from cows inseminated with conventional semen $(P=0.007)$. Birth weight also tended to be greater for calves born from cows treated with seminal plasma than from cows treated with saline $(P=0.097)$. Although the interaction was not significant, examination of means indicated that the 
Table 3. Characteristics of heifer calves as affected by intrauterine infusion of saline or seminal plasma at insemination $^{1}$

\begin{tabular}{lcc}
\hline Group and treatment & $\begin{array}{c}\text { Gestation length, } \\
\text { heifers (d) }\end{array}$ & $\begin{array}{c}\text { Birth weight, } \\
\text { heifers (kg) }\end{array}$ \\
\hline Primiparous; X-sorted semen & $272.5 \pm 0.6(72)$ & $32.2 \pm 0.6(72)$ \\
Saline & $272.6 \pm 0.6(73)$ & $33.9 \pm 0.6(71)$ \\
Seminal plasma & $273.3 \pm 0.6(82)$ & $33.3 \pm 0.6(79)$ \\
Multiparous; X-sorted semen & $273.6 \pm 0.5(90)$ & $33.9 \pm 0.6(87)$ \\
$\quad$ Saline & $272.7 \pm 0.6(72)$ & $31.8 \pm 0.6(69)$ \\
Seminal plasma & $273.9 \pm 0.7(50)$ & $31.6 \pm 0.7(49)$ \\
Multiparous; conventional semen & 0.240 & 0.097 \\
Saline & 0.335 & 0.025 \\
Seminal plasma & 0.155 & 0.258 \\
-value & 0.800 & 0.007 \\
Treatment & 0.694 & 0.283 \\
Group & 0.919 & 0.488 \\
Contrast: parity & 0.470 & \\
Contrast: semen type & & \\
Treatment $\times$ group & & \\
Contrast: treatment $\times$ parity & & \\
Contrast: treatment $\times$ semen type & & \\
1Data are LSM \pm SEM (no.). &
\end{tabular}

effect of X-sorted semen occurred only for calves from cows inseminated with X-sorted semen, particularly for primiparous cows. The effect of seminal plasma was significant $(P=0.019)$ if analysis was limited to the subset of calves born using X-sorted semen.

\section{DISCUSSION}

Results reported here do not support the hypothesis that seminal plasma improves fertility at first service in lactating Holstein cows. In general, we detected no effects of seminal plasma on fertility, except for a tendency for seminal plasma to reduce pregnancy per $\mathrm{AI}$ at d 32 and calving per AI for multiparous cows inseminated with conventional semen. Among cows inseminated with X-sorted semen, however, birth weight differed between heifer calves born from cows treated with seminal plasma and those born from cows treated with saline. This result suggests that changes in the endometrial environment caused by seminal plasma may change the developmental program of the resulting embryo in a way that causes increased birth weight in heifers. The lack of effect of seminal plasma on birth weight of calves derived from conventional semen may reflect the presence of residual amounts of seminal plasma in straws of conventional semen.

The lack of a positive effect of seminal plasma on fertility may indicate that seminal plasma does not have a biological role in regulating female reproductive function in cattle. Perhaps differences in the timing of development relative to insemination in the cow versus the mouse make postcoital uterine inflammation important in one species but not another. For example, the blastocyst forms at $\mathrm{d} 3.5$ in the mouse and implanta- tion into the uterus takes place at d 4.0 (Kojima et al., 2014). These events occur later after insemination in the cow so that, perhaps, inflammatory responses in the uterus are less important for subsequent development. The bovine embryo does not enter the uterus until d 4 or 5 after ovulation (Hackett et al., 1993), the blastocyst typically forms at $\mathrm{d} 7$ (Betteridge and Fléchon, 1988), and attachment of the embryo to the endometrial epithelium is first initiated around d 20 of gestation (King et al., 1981).

It may also be that inflammation associated with semen deposition during natural mating is important for establishment of pregnancy in cattle but the treatment regimen used in the present experiment did not mimic the inflammation typically induced by natural mating. In the mare, intrauterine infusion of spermatozoa and seminal plasma provoked a greater infiltration of polymorphonuclear leukocytes in the uterus than did seminal plasma alone (Kotilainen et al., 1994). In the gilt, seminal plasma reduced the leukocytic response to intrauterine deposition of spermatozoa (Rozeboom et al., 1999).

The overall fertility in the herd used in the current experiment was high; the pregnancy per AI at d 30 was $45.4 \%$. Disorders in uterine function corrected by seminal plasma infusion might have had low incidence in the herd so that seminal plasma was of limited value. If so, seminal plasma might be more beneficial for improving fertility in herds of cows in which fertility is low. In the study of Odhiambo et al. (2009), in which there was a nonsignificant, numerical increase in fertility of lactating cows associated with seminal plasma treatment, pregnancy per AI for control cows was $33.2 \%$, lower than that in the current study. 
It is possible that the amounts of seminal plasma introduced in the uterus did not mimic exposure of the uterus to seminal plasma after natural mating, where semen deposition occurs in the vagina and an unknown amount of seminal molecules is transferred to the uterus, either bound to spermatozoa (Plante et al., 2016) or transported by contractions of the reproductive tract (Hawk, 1987). Conceivably, introduction of too much seminal plasma into the uterus may result in changes in endometrial function different from what is induced by exposure to molecules in seminal plasma after natural mating. Regardless, our in vitro data support a functional response of endometrial cells to the seminal plasma used for intrauterine infusion. The data observed here confirmed that the seminal plasma used for intrauterine infusion was bioactive because of the increase in $I L 1 B$ and $I L 6$ expression in BEND cells. Changes in gene expression in BEND cells caused by seminal plasma were less than previous reports using cultures of endometrial explants (Ibrahim et al., 2019). In particular, seminal plasma did not affect expression of CSF2. This inconsistency could reflect that BEND cells, although derived from endometrium, are immortalized, and that regulatory interactions between various cell types present in endometrial explants are not possible in cultured BEND cells.

Fetal losses from d 60 to calving were higher for multiparous cows than for primiparous cows. There is one report that pregnancy loss from d 30 to 58 was higher for multiparous cows than for primiparous cows (Santos et al., 2009), whereas there was no effect of parity on pregnancy losses in other experiments (see, for example, Jousan et al., 2005, and Santos et al., 2017). Large numbers of animals are required to obtain good estimates on pregnancy loss, and further work is required to determine the effect of parity as well as farm $\times$ parity interactions on pregnancy loss.

Several reports indicate that alterations of maternal physiology around the time of conception can modify development of the embryo to affect postnatal phenotype (Hansen et al., 2016; Fleming et al., 2017). Indeed, seminal plasma may function to program postnatal development, as reported for exposure of female mice to secretions of male seminal vesicles (Bromfield et al., 2014). Consistent with this idea was the finding that heifer calves born from females treated with seminal plasma were heavier at birth than heifers from females treated with saline, provided dams were inseminated with X-sorted semen. We need to be cautious in interpreting interactions with semen type because different sires were used for X-sorted semen than for conventional semen. It is possible, however, that a developmental programming effect of seminal plasma would be greater for calves derived from cows inseminated with $\mathrm{X}$-sorted semen because of the absence of seminal plasma during the sex-sorting process. The lack of effect of seminal plasma on birth weight in calves from conventional semen might be because some seminal plasma remains in extended semen. Numerically, the effect of seminal plasma was more pronounced for primiparous cows inseminated with X-sorted semen than for multiparous cows inseminated with $\mathrm{X}$-sorted semen; more work is needed to assess the nature of the effect of seminal plasma on birth weight. Additionally, future longitudinal studies of the calves born in this study will reveal additional information regarding the consequences of seminal plasma exposure of the dam on postnatal development of the resultant offspring.

It is notable that birth weights differed between calves derived from $\mathrm{X}$-sorted semen versus conventional semen. It is possible that this effect simply reflects sire. However, the use of reverse-sorted semen for in vitro production of embryos has been reported to have several consequences for the offspring, including reduced milk yield when female offspring themselves calve (Siqueira et al., 2017). It should be noted that birth weights were low in the current study compared with typical values for Holsteins (see, for example, Kamal et al., 2014). The reasons for this are not known but could be related to gestation length, which was also short (see Nogalski and Piwczyński, 2012). Gestation length is related to calf birth weight (Nogalski and Piwczyński 2012). These observations indicate the need to repeat observations regarding effects of semen type and seminal plasma on the calf birth weight.

\section{ACKNOWLEDGMENTS}

The authors thank the owners and staff of Alliance Dairies (Trenton, FL) for allowing use of the cows and facilities. Thanks to the reproduction staff for support and assistance, in particular, Nilo Francisco and Bong Velasquez and other members of the reproduction team, who performed intrauterine infusions. The authors also thank University of Florida laboratory members Adriana Zolini, Paula Tribulo, Thiago Amaral, Guilherme Marquezini, and Fernanda Cavallari de Castro for technical assistance. Research was supported in part by Select Sires Inc. (Plain City, OH) and the L. E. "Red" Larson Endowment (Gainesville, FL).

\section{REFERENCES}

Alghamdi, A. S., D. N. Foster, and M. H. Troedsson. 2004. Equine seminal plasma reduces sperm binding to polymorphonuclear neutrophils (PMNs) and improves the fertility of fresh semen inseminated into inflamed uteri. Reproduction 127:593-600.

Alghamdi, A. S., B. J. Lovaas, S. L. Bird, G. C. Lamb, A. K. Rendahl, P. C. Taube, and D. N. Foster. 2009. Species-specific interaction of 
seminal plasma on sperm-neutrophil binding. Anim. Reprod. Sci. 114:331-344.

Betteridge, K. J., and J. E. Fléchon. 1988. The anatomy and physiology of pre-attachment bovine embryos. Theriogenology 29:155-187.

Bromfield, J. J. 2016. A role for seminal plasma in modulating pregnancy outcomes in domestic species. Reproduction 152:R223R232.

Bromfield, J. J., J. E. Schjenken, P. Y. Chin, A. S. Care, M. J. Jasper, and S. A. Robertson. 2014. Maternal tract factors contribute to paternal seminal fluid impact on metabolic phenotype in offspring. Proc. Natl. Acad. Sci. USA 111:2200-2205.

Chow, P. H., and W. S. O. 1989. Effects of male accessory sex glands on sperm transport, fertilization and embryonic loss in golden hamsters. Int. J. Androl. 12:155-163.

Davies, D. C., G. Hall, G. Hibbitt, and H. D. Moore. 1975. The removal of the seminal vesicles from the boar and the effects on the semen characteristics. J. Reprod. Fertil. 43:305-312.

FASS. 2010. Guide for the Care and Use of Agricultural Animals in Research and Teaching. 3rd ed. FASS, Champaign, IL.

Faulkner, L. C., M. L. Hopwood, and J. N. Wiltbank. 1968. Seminal vesiculectomy in bulls. II. Seminal characteristics and breeding trials. J. Reprod. Fertil. 16:179-182.

Fleming, T. P., J. J. Eckert, and O. Denisenko. 2017. The role of maternal nutrition during the periconceptional period and its effect on offspring phenotype. Adv. Exp. Med. Biol. 1014:87-105.

Hackett, A.J., R. Durnford, R. Mapletoft, and G. Marcus. 1993. Location and status of embryos in genital tract of superovulated cows 4 to 6 days after insemination. Theriogenology 40:1147-1153.

Hansen, P. J., K. B. Dobbs, A. C. Denicol, and L. G. Siqueira. 2016. Sex and the preimplantation embryo: implications of sexual dimorphism in the preimplantation period for maternal programming of embryonic development. Cell Tissue Res. 363:237-247.

Hansen, P. J., M. P. Hoggard, and A. C. Rathwell. 1987. Effects of stallion seminal plasma on hydrogen peroxide release by leukocytes exposed to spermatozoa and bacteria. J. Reprod. Immunol. $10: 157-166$.

Hawk, H. W. 1987. Transport and fate of spermatozoa after insemination of cattle. J. Dairy Sci. 70:1487-1503.

Howe, G. R., and D. L. Black. 1963. Spermatozoan transport and leucocytic responses in the reproductive tract of calves. J. Reprod. Fertil. 6:305-311.

Ibrahim, L. A., J. A. Rizo, P. L. P. Fontes, G. C. Lamb, and J. J. Bromfield. 2019. Seminal plasma modulates expression of endometrial inflammatory mediators in the bovine. Biol. Reprod. 100:660671. https://doi.org/10.1093/biolre/ioy226.

Jousan, F. D., M. Drost, and P. J. Hansen. 2005. Factors associated with early and mid-to-late fetal loss in lactating and nonlactating Holstein cattle in a hot climate. J. Anim. Sci. 83:1017-1022.

Kamal, M. M., M. Van Eetvelde, E. Depreester, M. Hostens, L. Vandaele, and G. Opsomer. 2014. Age at calving in heifers and level of milk production during gestation in cows are associated with the birth size of Holstein calves. J. Dairy Sci. 97:5448-5458.

Katila, T. 2012. Post-mating inflammatory responses of the uterus. Reprod. Domest. Anim. 47:31-41.

King, G. J., B. A. Atkinson, and H. A. Robertson. 1981. Development of the intercaruncular areas during early gestation and establishment of the bovine placenta. J. Reprod. Fertil. 61:469-474.
Kojima, Y., O. H. Tam, and P. P. Tam. 2014. Timing of developmental events in the early mouse embryo. Semin. Cell Dev. Biol. 34:65-75.

Kotilainen, T., M. Huhtinen, and T. Katila. 1994. Sperm-induced leukocytosis in the equine uterus. Theriogenology 41:629-636.

Mattner, P. E. 1968. The distribution of spermatozoa and leucocytes in the female genital tract in goats and cattle. J. Reprod. Fertil. $17: 253-261$.

Nogalski, Z., and D. Piwczyński. 2012. Association of length of pregnancy with other reproductive traits in dairy cattle. Asian-australas. J. Anim. Sci. 25:22-27.

O'Leary, S., M. J. Jasper, G. M. Warnes, D. T. Armstrong, and S. A. Robertson. 2004. Seminal plasma regulates endometrial cytokine expression, leukocyte recruitment and embryo development in the pig. Reproduction 128:237-247.

Odhiambo, J. F., D. H. Poole, L. Hughes, J. M. DeJarnette, E. K. Inskeep, and R. A. Dailey. 2009. Pregnancy outcome in dairy and beef cattle after artificial insemination and treatment with seminal plasma or transforming growth factor beta-1. Theriogenology 72:566-571.

Plante, G., B. Prud'homme, J. Fan, M. Lafleur, and P. Manjunath. 2016. Evolution and function of mammalian binder of sperm proteins. Cell Tissue Res. 363:105-127.

Robertson, S. A. 2005. Seminal plasma and male factor signalling in the female reproductive tract. Cell Tissue Res. 322:43-52.

Rozeboom, K. J., M. H. Troedsson, H. H. Hodson, G. C. Shurson, and B. G. Crabo. 2000. The importance of seminal plasma on the fertility of subsequent artificial inseminations in swine. J. Anim. Sci. 78:443-448

Rozeboom, K. J., M. H. Troedsson, T. W. Molitor, and B. G. Crabo. 1999. The effect of spermatozoa and seminal plasma on leukocyte migration into the uterus of gilts. J. Anim. Sci. 77:2201-2206.

Santos, J. E., H. M. Rutigliano, and M. F. Sá Filho. 2009. Risk factors for resumption of postpartum estrous cycles and embryonic survival in lactating dairy cows. Anim. Reprod. Sci. 110:207-221.

Santos, V. G., P. D. Carvalho, C. Maia, B. Carneiro, A. Valenza, and P. M. Fricke. 2017. Fertility of lactating Holstein cows submitted to a Double-Ovsynch protocol and timed artificial insemination versus artificial insemination after synchronization of estrus at a similar day in milk range. J. Dairy Sci. 100:8507-8517.

Schuberth, H. J., U. Taylor, H. Zerbe, D. Waberski, R. Hunter, and D. Rath. 2008. Immunological responses to semen in the female genital tract. Theriogenology 70:1174-1181.

Shin, S. J., D. H. Lein, V. H. Patten, and H. L. Ruhnke. 1988. A new antibiotic combination for frozen bovine semen. 1. Control of mycoplasmas, ureaplasmas, Campylobacter fetus ssp. venerealis and Haemophilus somnus. Theriogenology 29:577-591.

Siqueira, L. G. B., S. Dikmen, M. S. Ortega, and P. J. Hansen. 2017. Postnatal phenotype of dairy cows is altered by in vitro embryo production using reverse X-sorted semen. J. Dairy Sci. 100:58995908

Souza, A. H., H. Ayres, R. M. Ferreira, and M. C. Wiltbank. 2008. A new presynchronization system (Double-Ovsynch) increases fertility at first postpartum timed AI in lactating dairy cows. Theriogenology 70:208-215. 